\title{
Olfaction and young children's preferences: A comparison of odor and visual cues
}

\author{
RICHARD A. FABES \\ Arizona State University, Tempe, Arizona \\ and \\ ERIK E. FILSINGER \\ University of Alabama, Tuscaloosa, Alabama
}

\begin{abstract}
This research compared the relative contributions of odor and visual cues in determining young children's preferences. Thirty-two children were assigned randomly to one of four groups that differed in the order in which odorants and colors were presented. The children were tested in two sessions which differed in terms of the odorant concentrations (16 or 1,600 times threshold). On each occasion, the children were presented with four bottles which contained colored flowers (red, purple, orange, and yellow) and different odors (benzaldehyde, dimethyl disulfide, androstenone, and no odor). The children were asked to verbally indicate their odor preferences and then were asked to select the bottles they preferred. The results indicated that children failed to differentiate among the odors via self-report indices. At low concentrations, children's behavioral preferences were significantly influenced by color (red and purple were most preferred, yellow and orange were least preferred), but not odor. At higher concentrations, children's behavioral preferences were significantly influenced by odor (benzaldehyde most preferred, dimethyl disulfide least preferred), but not color. The results suggest that although there are general color preferences, children's odor preferences depend on intensity. Issues relevant to future research are discussed.
\end{abstract}

Although the idea that odor signals may repel, attract, or influence humans is not new, very little is actually known about the role that odor may play in human interaction. There has been, however, an increasing number of research articles which have found evidence to suggest that humans have a greater capacity to receive and respond to chemical communication via olfaction than previously thought (Cain, 1977; Doty, in press; Fabes \& \& Filsinger, in press; Filsinger, Braun, Monte, \& Linder, 1984; Filsinger \& Fabes, 1985; Porter \& Moore, 1981). While most of this research has been primarily concerned with adult behaviors, Filsinger and Fabes (1985) reviewed evidence which suggests that odor communication may play an even greater role for children.

Several studies have focused upon the olfactory capabilities of the human infant and fetus (Carmichael, 1970; Cernoch \& Porter, 1985; Engen \& Lipsitt, 1965; Lipsitt, Engen, \& Kaye, 1963; Self, Horowitz, \& Paden, 1972).

\footnotetext{
This research was supported in part by a Faculty Release Award granted to the first author by the Department of Family Resources and Human Development, Arizona State University. The authors wish to thank Woodrow Monte for his technical assistance and advice in the preparation of the materials used in this research. We also thank Barry Arbuckle, Angela Vance, and Becky Rudd for assisting in data collection. Finally, appreciation is expressed to Kathy Ritchie, Director of Child Laboratory Programs, and the teachers, staff, parents, and children of the Arizona State University Child Development Lab for their cooperation. Reprint requests should be sent to Richard A. Fabes, Department of Family Resources and Human Development, Arizona State University, Tempe, AZ 85287.
}

These studies have found that olfaction is one of the first senses to develop and precedes the full development of vision and hearing. Carmichael (1970), in his review of early sensory development, points out that the olfactory structures have been found to be among the earliest myelinated in the fetus. Additional support for the significant role that olfactory communication may play in early development is provided by studies (e.g., Cernoch \& Porter, 1985; MacFarlane, 1975; Russell, 1976) which suggest that infants may come to recognize their mothers by their scents (and vice versa; e.g., see Porter, Cernoch, \& McLaughlin, 1983; Porter \& Moore, 1981). No other scent seems to be as rapidly discriminated, and this may suggest that learning in this case is predisposed to occur quickly with these particular stimuli (Hofer, 1981).

Compared with research conducted on infants, there has been relatively little work that has examined olfactory functions in children older than infants. Doty (in press) points out that older children recognize and respond to a wide range of odorants. For example, Doty (1986; Doty, Shaman, Applebaum, Giberson, Sikorski, \& Rosenberg, 1984) has found that boys and girls correctly identify many odorants and, by the age of 10 , can identify odorants at comparable-to-adult levels. Other data suggest that, in some cases, children prefer odorants that adults and/or infants do not (Stein, Ottenberg, \& Roulet, 1958).

Such evidence supports the need to further examine olfactory responsiveness in children. Although there is a considerable accumulation of evidence regarding the de- 
velopment of olfaction, numerous questions remain. In particular, very little evidence has compared the influence of odor cues with those of other sensory cues. The present study examines whether visual preferences in children may be diminished by the presence of odor cues presented at two different concentration levels that were just beyond threshold.

There has probably been more research on vision than on all other modalities put together. The major reason for this appears to be the ascribed importance and dominance of vision for human environmental adaptation. Perhaps the best known examples of visual dominance are the "visual cliff" experiments (e.g., Gibson \& Walk, 1960), in which young humans and other animals avoid the "deep side" of the cliff despite the fact that they can feel the firm glass over it. These findings clearly demonstrate that, in humans as young as infants, vision is dominant over the haptic senses.

However, other data suggest that the visual dominance found in the "visual cliff" experiments may be limited and that, under certain conditions, visual cues may be overcome. For example, Richards and Radar (1981) found that infants who had developed the ability to crawl very early were guided more by their sense of touch and tended to continue to crawl over the "deep side." Despite such findings, relatively little attention has been paid to conditions under which other sensory information diminishes the salience of visual cues. This has been especially true in terms of olfaction. The purpose of the present study was to compare the relative contributions of odor and visual cues in determining children's preferences.

\section{METHOD}

\section{Subjects}

Thirty-two preschoolers (18 males and 14 females) attending classes at the child development lab at Arizona State University were included in the study. The children, who ranged in age from 38 to 67 months at the time of participation ( $M=49.97$ months), were primarily from white, middle-class homes.

\section{Design}

To detect the possible effects of odor and visual cues upon children's judgments and preferences, two stimulus trials were run. These trials differed in terms of the concentration levels of the odor chemicals. The trials consisted of having the children smell four different odors (androstenone, benzaldehyde, dimethyl disulfide, and no odor) in bottles which also contained four different colored flowers (red, yellow, orange, and purple). The presentation of odor and flower color was counterbalanced using a Greco-Latin square procedure (Winer, 1971). This procedure randomly combines two orthogonal Latin squares and allows for the independent evaluation of systematic effects due to the presentation of both odor and color.

\section{Materials}

Four odor conditions were used in this study. The first was alpha androstenone (5 alpha androst-16-en-3-one, Sigma No. A8088). Androstenone is a human body odor associated with sweat and musk (Brooksbank, Brown, \& Gustafsson, 1974). The second odorant was dimethyl disulfide (DMDS, Sigma No. D8501). DMDS is a human odorant associated with saliva and anogenital secretions and appears to be produced by naturally occurring bacteria (Alberts \& Gubernick, 1983). The third odorant used in this study was benzaldehyde (Sigma No. B6259). Benzaldehyde is a common food artificial flavoring of essential oil of almond. Finally, a no-odor condition was included as a control. The odors used in this study were selected because they have been successfully and safely used in previous research with adults (e.g., Filsinger et al., 1984) and because they represent a broad range of odorants that differ in psychophysical qualities.

For the first stimulus trial, the three chemicals were diluted in pure glycerol to a concentration that was 16 times their maximum threshold sensitivity values as cited in Fazzalari (1978). The specific maximum threshold values used in this research were $1.5,0.15$, and $0.0029 \mathrm{ppm}$ for benzaldehyde, DMDS, and androstenone respectively. The 16-fold factor was selected on the basis of research that suggests that failure to detect the odor at this concentration defines a specific anosmic for that odor (Amoore, 1979). For the second stimulus trial, the concentrations of the chemicals were increased by a factor of 100 over the concentration levels used in the first stimulus trial. In olfactory terms, this increase is relatively moderate (e.g., see Dodd \& Van Toller, 1983).

Initially, $1 \mathrm{ml}$ of each chemical was placed in the bottom of a Wheaton 16-oz $(480-\mathrm{ml})$ glass bottle. At the end of each day, an additional $.5 \mathrm{ml}$ of each chemical was added to each appropriate bottle and the chemicals were stored overnight at room temperature for use the next day. Each bottle also contained a colored plastic flower. These flowers had been baked in an oven for $12 \mathrm{~h}$ at a temperature of $200^{\circ} \mathrm{F}$ in order to ensure that they not emit any contaminating odor.

\section{Procedure}

Children were assigned randomly to one of four groups, which differed in the order in which the four odors and flowers were presented $(n=8)$. Each child was individually escorted into the experimental room by one of four experimenters (two males and two females), each of whom had received extensive training prior to the experiment in order to ensure that the procedures they used were similar throughout the study.

After rapport was established, each child was introduced to the "face game" and given a brief description and demonstration of how it was played. This game consisted of five drawn faces pasted onto a cardboard strip. The faces differed from left to right in terms of the degree of frown or smile on each face. These faces constituted a 5-point rating scale and differed in the degree to which the mouth on each face was smiling or frowning. A score of 5 (maximumsmile face) indicated the most positive response and a score of one (maximum-frown face) indicated the most negative response.

After the experimenter was certain that the child understood the smile/frown face procedure, he/she presented the child with four glass jars containing the odor chemicals and flowers arranged in their predetermined order. The child was asked to clean and blow his/her nose with a Kleenex and then asked to smell each jar, one at a time, and to indicate whether or not he/she smelled anything. Each bottle was placed under the child's nose and the glass stopper was then removed. The bottle was waved under the child's nose while the child sniffed. The stopper was then replaced and the bottle put back. If the child affirmed that he/she smelled something in the jar, then the child was asked to indicate whether the smell was pleasant or not by pointing to one of the five smile/frown faces. If the child indicated that he/she could not smell anything in the jar, the experimenter requested him/her to smell the jar once more. If, after this second attempt, the child still reported that he/she could not smell anything, the experimenter proceeded on to the next bottle. In each case, the experimenter paused $20 \mathrm{sec}$ in between the child's response and the presentation of the next bottle.

After all four bottles had been smelled, and the child had responded to the face game, the child was asked to smell each of the bottles again and then requested to pick the one bottle that he/she 
liked the best. If the child asked to smell the bottles again, he/she was so allowed. The child's selected bottle was then removed and the child was asked to smell the remaining three bottles and pick the bottle that he/she liked the best from among the remaining three bottles. The selected bottle was again removed and the procedure was repeated, with the child smelling and choosing his/her favorite from the remaining two bottles. This procedure produced a behavioral scaling of the odors and flowers in order of their selected preference.

Approximately 1 week later, each child was brought back into the experimental room for the second trial with the same experimenter he/she had worked with during the first trial. The second trial was procedurally identical to the first, except that the concentration levels of the chemicals had been increased by a factor of 100 over the levels used in the first trial.

\section{RESULTS}

Each trial produced two types of dependent measures. These included: (1) the child's verbal judgments of the odors, and (2) the child's behavioral preferences in terms of his/her rank-ordered selection of the four bottles. Analyses failed to reveal any significant differences for sex of the children or the experimenter. Therefore, these factors were eliminated from the analyses presented below.

Analysis of the data utilized procedures identified by Winer (1971) for analysis of variance of Greco-Latin square designs with repeated measures (Plan 7). In the present study, separate analyses were performed for each trial. Within each trial, there existed one between-subject factor (presentation-order group) and three within-subject factors (bottle position, odor condition, and flower color). To obtain unbiased estimates of the differential main effects of the within-subject factors, all interactions are assumed to be negligible. Furthermore, the expected values of the mean squares of these within-subject main effects do not involve a between-subjects component (Winer, 1971).

\section{Stimulus Trial 1}

Analysis of the children's self-report preference data obtained during the first stimulus trial revealed a significant main effect only for bottle position $[F(3,84)=5.86$, $p<.011$. Means and standard deviations for all the groups combined for the first, second, third, and fourth

Table 1

Mean Rank Order Selection Scores (and Standard Deviations) by Flower Color and Odor, Stimulus Trial 1*

\begin{tabular}{|c|c|c|}
\hline Condition & $M$ & $S D$ \\
\hline \multicolumn{3}{|c|}{ Flower Color } \\
\hline Purple & 2.25 & 1.22 \\
\hline Red & 2.22 & 1.04 \\
\hline Orange & 2.59 & 1.07 \\
\hline Yellow & 2.94 & 1.05 \\
\hline \multicolumn{3}{|c|}{ Odor } \\
\hline Dimethyl Disulfide & 2.47 & 1.08 \\
\hline No Odor & 2.44 & 1.01 \\
\hline Androstenone & 2.47 & 1.19 \\
\hline Benzaldehyde & 2.63 & 1.24 \\
\hline
\end{tabular}

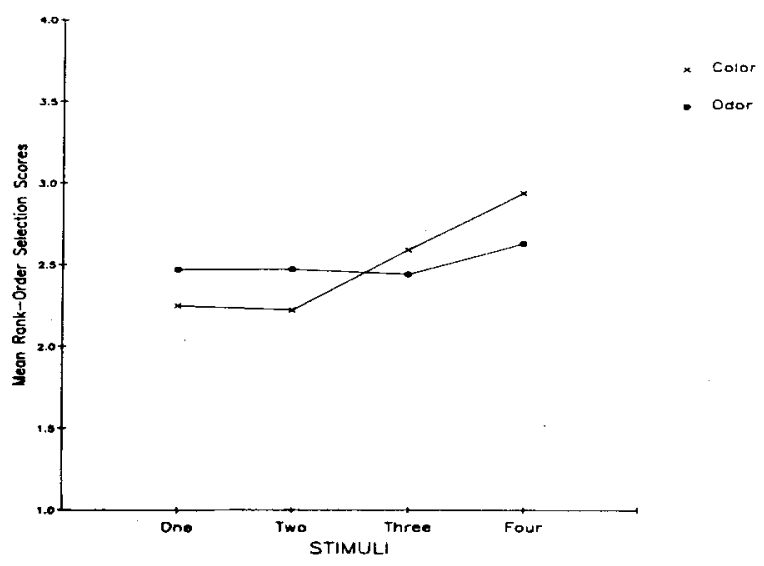

Figure 1. Mean rank-order selection scores as a function of flower color and odor in Stimulus Trial 1. (Note that Stimuli 1, 2, 3, and 4 represent the color purple, red, orange, and yellow, and the odors dimethyl disulfide, no odor, androstenone, and benzaldehyde, respectively. Higher mean scores represent lower preferences.)

bottles were 2.44 (1.52), 2.69 (1.33), 3.22 (1.01), and 3.72 (1.59), respectively. Thus, these data indicate that the children tended to anchor their responses on the left side of the smile/frown face response guide and progressively moved to the right with each successive presentation. Since the faces to the left of the child were the frown faces, it is no surprise the the bottles that were presented first had lower self-report preference scores than the bottles that were presented later. This trend was found to occur regardless of the odor or of the color of the flower in the bottles.

The data regarding the children's behavioral selection of the bottles revealed a significant main effect only for flower color $[F(3,84)=2.71, p<.05]$. Table 1 presents the overall mean rank-order selection scores, and their standard deviations, for the four flower colors and four odor conditions. Inspection of the mean scores in Table 1, where a lower score represents a greater overall preference selection, reflects the basis for the significant main effect for flower color noted above. Children tended to systematically prefer the bottles that contained the flowers colored red and purple; orange came next, and yellow flowers clearly were the least preferred color. Individual comparisons of these differences indicated that both the red and purple flowers were significantly more preferred than were the yellow flowers $(p s<.05)$. Examination of the means for the odor conditions indicates that there were no overall differences in preferences for the odors. In fact, the means for these odor conditions were almost identical to one another. Thus, the behavioral selections of the children during the first trial, in which the concentrations were just above threshold levels, primarily were based upon visual rather than olfactory cues. Figure 1 graphically represents this comparison.

\section{Stimulus Trial 2}

Analysis of the children's self-report data during the second stimulus trial, in which concentrations were at 
levels 100 times those used in the first stimulus trial, revealed the same trend as that found in the first trial, namely a significant main effect for bottle position only $[F(3,84)=5.86, p<.01]$. Once again, the children tended to rate the bottles presented first lower than those presented later. Combined self-report preference means (and standard deviations) for the first, second, third, and fourth bottles were $2.38(1.60), 2.66(0.83), 3.16(1.32)$, and $3.72(1.49)$, respectively.

Means and standard deviations for the rank-order selections of the children during the second trial are presented in Table 2 for each flower color and odor. Inspection of Table 2 reveals that the trend found for color preference during the first trial, with purple and red being most preferred and orange and yellow less preferred, is still present during this trial. However, the trend was less dramatic than it was during the first trial, whereas the trend regarding odor preferences was more pronounced. Analysis of these data resulted in a significant main effect for odor $[F(3,84)=6.44, p<.01]$ but not for color $(F<1.00)$. Benzaldehyde was the most preferred odor, and dimethyl disulfide was clearly the least preferred odor. Individual comparisons indicated that dimethyl disulfide was significantly less preferred than benzaldehyde $(p<.01)$, androstenone $(p<.05)$, or no odor $(p<.05)$. In addition, benzaldehyde was significantly more preferred than the no-odor condition $(p<.05)$. Thus, the behavioral selections of the children during the second trial were primarily based upon the differential reactions to benzaldehyde and dimethyl disulfide. Visual cues were not found to influence the children's selections during this stimulus trial. Figure 2 graphically represents this comparison.

\section{DISCUSSION}

The results of this study revealed that the basis for the selection of preferences varied as a function of the concentration levels of the odorants. In the first trial, in which the concentrations were weak (just above threshold), the results revealed a significant main effect for color but not for odor. Children tended to base their judgments of preferences according to visual cues with clear preferences

Table 2

Mean Rank Order Selection Scores (and Standard Deviations) by Flower Color and Odor, Stimulus Trial 2*

\begin{tabular}{|c|c|c|}
\hline Condition & $M$ & $S D$ \\
\hline \multicolumn{3}{|c|}{ Flower Color } \\
\hline Purple & 2.31 & 1.12 \\
\hline Red & 2.41 & 1.10 \\
\hline Orange & 2.59 & 1.13 \\
\hline Yellow & 2.69 & 1.15 \\
\hline \multicolumn{3}{|c|}{ Odor } \\
\hline Dimethyl Disulfide & 3.16 & 0.88 \\
\hline No Odor & 2.56 & 1.13 \\
\hline Androstenone & 2.41 & 1.01 \\
\hline Benzaldehyde & 1.88 & 1.10 \\
\hline
\end{tabular}

Note-Lower scores represent greater preference selections.

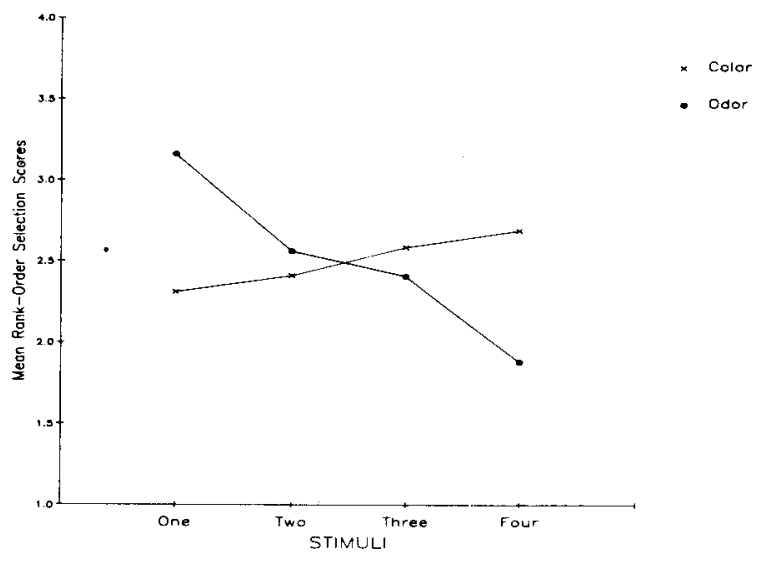

Figure 2. Mean rank-order selection scores as a function of flower color and odor in Stimulus Trial 2. (Note that Stimuli 1, 2, 3, and 4 represent the colors purple, red, orange, and yellow, and the odors dimethyl disulfide, no odor, androstenone, and benzaldehyde, respectively. Higher mean scores represent lower preferences.)

for the colors of purple and red over orange and yellow. Although a similar trend was present in the second trial, in which odors were at concentrations 100 times the levels used in the first trial, it was not found to be significant. However, a significant main effect for odor was found. This effect was due to the children's consistent tendency to choose benzaldehyde as their most preferred odorant and dimethyl disulfide as their least preferred. These results indicate that although there are generally consistent color preferences, children's preferences in the case of odors depend on intensity.

The finding that there were no significant odor preferences in the first trial but that there were significant odor preferences in the second trial, in which the odorants were presented at higher concentrations, leads one to question whether the children in our study actually detected the lower concentrations. Such an assumption is based upon data that suggest an inverse relationship between preferences and odor intensity (e.g., Moskowitz, 1977). Based upon findings such as these, one would expect preferences for the odorants to be greater at the lower concentrations than at the higher concentrations. Furthermore, that odor preferences were not present to any degree at levels established to identify anosmia in adults (Amoore, 1979) could lead one to question whether children are sensitive to odors presented at or just above adult thresholds. However, several studies have concluded that children are not less, and perhaps are more, sensitive to odors than are adults (see Doty, in press, and McCartney, 1968, for reviews). Although odor sensitivity in general may be comparable for children and adults, other studies suggest that sensitivity to particular types of odors changes with age. For example, Koelega and Koster (1974) noted that prepubescent children were less able to detect musk odors at levels detected by adults. More recently, Laing and Clark (1983) found that some changes in odor perception occur with puberty. They found that preferences for certain food-related odors change during puberty. Finally, 
data from several studies suggest that young children evidence less displeasure in response to certain odorants, particularly human odorants, found to be disagreeable by adults and older children (Engen, 1974, 1982; Moncrieff, 1966; Peto, 1936). For example, Lipsitt, Engen, Bloom, and Jennings (1975) found that 1- and 2-year-old children do not mind the smell of dimethyl disulfide, whereas their parents distinctly do not like its smell. Such findings suggest that researchers should pay close and cautious attention to developmental factors when studying human odor communication, and that one must be careful about assuming that established thresholds for adults apply directly to children. This seems to be particularly true when comparing prepubescent children with adults and also in the use of odorants that appear to have biological significance.

The results of the self-report preference data in the present study did not show the same kinds of trends found for the behavioral preference data. For both trials, children failed to differentiate between the odors in terms of self-reported preferences. The reason for this discrepancy between self-report and behavioral preference data was due to the children's tendency to anchor their self-report responses toward one side of the smile/frown scale and then to progressively move to the other side with each successive presentation. It is possible that the children in this study did not truly understand the instructions for the self-report format. However, other researchers have noted similar problems in terms of children's use of self-report indices in odor research. For example, Doty (in press) reports that young children often tend to respond in the positive in situations in which "yes" or "no" is required as a response. This was found to be true in our study as well. When children were asked if they had smelled "anything," few $(n=2)$ reported that they had not. Furthermore, children have also been found to be more likely to respond in the affirmative when asked the question "Does it smell pretty?" than they do when asked the question "Does it smell ugly?" (Doty, in press; Engen, 1974). As suggested by Engen (1986), a forced-choice procedure, whereby children are asked whether the odor was good or bad (in a counterbalanced fashion), avoids some of the response bias noted above, and its use in the present study may have produced more reliable self-report data.

Such concerns point to the problems inherent in selfpresentation, comprehension, and communication in terms of children's ability to reliably use verbal indices of olfactory preferences. These concerns also point to the importance of utilizing alternative methods for examining young children's olfactory responsiveness. For example, measuring children's reactions via facial coding (e.g., Ekman, 1972) or via psychophysiological measures (heart rate, skin conductance, etc.) may provide promising methods for future research. Steiner (1979) has reliably distinguished hedonic reactions to olfactory (and oral) stimuli via facial expressions in children and adults, although Lipsett et al. (1975) failed to find that facial ex- pressions were related to children's preferences. However, we suggest that if these measures are combined with other types of data, self-report and behavioral data, the possibility of accurately assessing children's responses to odors should be enhanced.

\section{REFERENCES}

Alberts, J. R., \& Gubernick, D. J. (1983). Reciprocity and resource exchange: A symbiotic model of parent-offspring relations. In L. A. Rosenblum \& H. Moltz (Eds.), Symbiosis in parent-offspring interactions. New York: Plenum Press.

Amoore, J. E. (1979). Directions for preparing aqueous solutions of primary odorants to diagnose eight types of specific anosmia. Chemical Senses \& Flavor, 4, 153-161.

Brooksbank, B. W. L., Brown, R., \& Gustafsson, J. S. (1974). The detection of 5-alpha-Androst-16-en-3-ol in human axillary sweat. $E x$ perientia, 30, 864-865.

CAIN, W. S. (1977). Physical and cognitive limitations on olfactory processing in human beings. In D. Muller-Schwarze \& M. M. Mozell (Eds.), Chemical signals in vertebrates. New York: Plenum Press.

Carmichael, L. (1970). Onset and early development of behavior. In P. Mussen (Ed.), Carmichael's manual of child psychology. New York: Wiley.

Cernoch, J. M., \& Porter, R. H. (1985). Recognition of maternal axillary odors by infants. Child Development, 56, 1593-1598.

DoDD, G., \& VAN TOLlER, S. (1983). The biochemistry and psychology of perfumery. Perfumer \& Flavorist, 8, 2-14.

DoTY, R. L. (1986). Gender and endocrine-related influences upon olfactory sensitivity. In H. L. Meiselman \& R. S. Rivlin (Eds.), Clinical measurement of taste and smell. New York: Macmillan.

DoTY, R. L. (in press). Ontogeny of human olfactory function. In W. Breipohl \& R. Apfelbach (Eds.), Ontogeny of olfaction in vertebrates. Berlin: Springer-Verlag.

Doty, R. L., Shaman, P., Applebaum, S. L., Giberson, R., SikorSK, L., \& RosenBerG, L. (1984). Smell identification ability: Changes with age. Science, 226, 1441-1443.

EkMaN, P. (1972). Universal and cultural differences in facial expression of emotion. In J. K. Cole (Ed.), Nebraska symposium on motivation, 1971. Lincoln: University of Nebraska Press.

ENGEN, T. (1974). Method and theory in the study of odor preference. In J. W. Johnston, D. G. Moulton, \& A. Turk (Eds.), Human response to environmental odors. New York: Academic Press.

ENGEN, T. (1982). The perception of odors. New York: Academic Press.

ENGEN, T. (1986). Children's sense of smell. In H. L. Meiselman \& R. S. Rivlin (Eds.), Clinical measurement of taste and smell. New York: Macmillan.

ENGEN, T., \& LiPsitT, L. P. (1965). Decrement and recovery of responses to olfactory stimuli in the human neonate. Journal of Comparative \& Physiological Psychology, 59, 312-316.

Fabes, R. A., \& Filsinger, E. E. (in press). Odor communication and parent-child interaction. In E. E. Filsinger (Ed.), Biosocial perspectives on the family. Beverly Hills, CA: Sage.

FAZZALARI, F. A. (1978). Compilation of odor and taste threshold values data. Philadelphia: Society for Testing and Materials.

Filsinger, E. E., Braun, J. J., Monte, W. C., \& Linder, D. (1984). Human responses to the pig (Sus scrofa) sex pheromone 5-alphaAndrost-16-en-3-one. Journal of Comparative Psychology, 98, 220-223.

FILSINGER, E. E., \& FABES, R. A. (1985). Odor communication, pheromones, and human families. Journal of Marriage and the Family, 47, 349-360.

GiBson, E. J., WALK, R. D. (1960). The "visual cliff." Scientific American, 202, 64-71.

HoFER, M. A. (1981). The roots of human behavior. San Francisco: W. H. Freeman.

Koelega, H. S., \& Koster, E. P. (1974). Some experiments on sex 
differences in odor perception. Annals of the New York Academy of Sciences, 237, 234-246.

LAING, D. G., \& ClaRK, P. J. (1983). Puberty and olfactory preferences in males. Physiology \& Behavior, 30, 591-597.

LiPsitT, L. P., Engen, T., Bloom, S. J., \& Jennings, V. (1975). Olfactory development in children to five years of age. Unpublished manuscript.

LIPSITT, L. P., ENGEN, T., \& KAYE, H. (1963). Developmental changes in the olfactory threshold of the neonate. Child Development, 34, 371-376.

MacFarlane, A. (1975). Olfaction in the development of social preferences in the human neonate. In Ciba Foundation Symposium, The human neonate in parent-infant interaction. Amsterdam: Associated Scientific Publishers.

MCCARTNEY, W. (1968). Olfaction and odours. New York: Springer. MonCRIEFF, R. W. (1966). Odor preferences. New York: Wiley.

Moskowitz, H. R. (1977). Intensity and hedonic functions for chemosensory stimuli. In M. R. Kare \& O. Maller (Eds.), The chemical senses and nutrition. New York: Academic Press.

PETo, E. (1936). Contribution to the development of smell feeling. British Journal of Medical Psychology, 15, 314-320.

Porter, R. H., Cernoch, J. M., \& McLaughin, F. J. (1983). Maternal recognition of neonates through olfactory cues. Physiology \& Behavior, 30, 151-154.

PorTer, R. H., \& MOORE, J. D. (1981). Human kin recognition by olfactory cues. Physiology \& Behavior, 27, 493-495.
RICHARDS, J. E., \& RADAR, E. (1981). Crawling-onset age predicts visual cliff avoidance. Journal of Experimental Psychology, 7, 382-387. RUSSELL, M. J. (1976). Human olfactory communication. Nature, 260, 520-522.

Self, P. A., Horowitz, F. D., \& Paden, L. Y. (1972). Olfaction in newborn infants. Developmental Psychology, 7, 349-363.

Stein, M., Ottenberg, P., \& Roulet, N. (1958). A study of the development of olfactory preferences. AMA Archives of Neurological Psychiatry, 80, 264-266.

Steiner, J. E. (1979). Human facial expressions in response to taste and smell stimulation. Advances in Child Development and Behavior, 13, 257-295.

WINER, B. J. (1971). Statistical principles in experimental design. New York: McGraw-Hill.

\section{NOTE}

1. It should be made clear that the present authors did not measure these maximum threshold values. Thus, they represent estimates, not true values.

(Manuscript received March 20, 1986; revision accepted for publication June 17, 1986.) 